\section{Why P6 medicine needs clinical psychology and a trans-cultural approach}

\author{
Nicola Luigi Bragazzi,1 \\ Giovanni Del Puente2
}

1School of Public Health, Department of Health Sciences (DISSAL), University of Genoa; 2DINOGMI, Department of Neuroscience, Rehabilitation, Ophthalmology, Genetics, Maternal and Child Health, Section of Psychiatry, University of Genoa, Italy

In the last decades, medicine has undergone profound and deep changes and challenges, such as the introduction of new medical devices and nanobiotechnologies, ${ }^{1-3}$ that have enabled the understanding of molecular pathogenesis at unprecedented levels. Nanogenomics and nanoproteomics represent the frontiers of biomedicine, ${ }^{4-7}$ paving the way for a personalized diagnosis and treatment, that is to say not just a one-size-fits-it-all therapy as before but a tailored, targeted therapeutics. There has been a shift from P0 medicine to a P6 model (where the six Ps stay for preventive, predictive, personalized, participatory, public and psycho-cognitive medicine). ${ }^{8}$ However, the introduction of new bio-techniques and procedures with their ethical implications as well as the emerging paradigm of a proactive medicine, focusing not only on acute diseases but above all on chronic pathologies, make psychology a not negligible and secondary component of this highly integrative approach. A patient is not only a disease, a clinical case or a genetic and biological entity but, first of all, a person and for a real personalized treatment a holistic integrated bio-psychosocial approach should be carried out. ${ }^{9-11}$ A good clinical practice should focus on the patientrecorded outcomes and measurements (PROMs), such as quality of life, customer satisfaction of the health-care process, if really wants to transform itself in a person-related and patient-centered medicine (as Carl Rogers and Michael Balint advocated). This would overcome paternalism and asymmetry in the physician-patient relationship and involving and empowering the patient and taking shared clinical decisions would result in a better health outcome.

Understanding the behavioral and cognitive aspects of the patient's decisions and preferences is fundamental and vital, considering that nowadays therapies are more complex being combination of drugs and that patient's adherence and compliance can have an impact on the success or failure of the treatment.

Moreover, a culturally competent perspective should inform clinician's approach in a globalized era, 12,13 considering that immigrants are more likely to suffer from mental health problems and psycho-social issues. ${ }^{14-17}$

For these reasons, psychology and a transcultural informed approach are an important component of the nowadays emerging P6 medicine.

\section{References}

1. Nicolini C, Bruzzese D, Cambria MT, et al. Recombinant Laccase: I. Enzyme cloning and characterization. J Cell Biochem 2013;114:599-605.

2. Bragazzi NL, Pechkova E, Scudieri D, et al. Recombinant Laccase: II. Medical biosensor. Crit Rev Eukaryot Gene Expr 2012;22: 197-203.

3. Nicolini C, Adami M, Sartore M, et al. Prototypes of newly conceived inorganic and biological sensors for health and environmental applications. Sensors (Basel) 2012;12:17112-27.

4. Bragazzi NL, Sivozhelezov V, Nicolini C. LeaderGene: a fast data-mining tool for molecular genomics. J Proteomics Bioinform 2011;4:83-6.

5. Racapé M, Bragazzi N, Sivozhelezov V, et al. SMILE silencing and PMA activation gene networks in HeLa cells: comparison with kidney transplantation gene networks. J Cell Biochem 2012;113:1820-32.

6. Orlando B, Bragazzi N, Nicolini C. Bioinformatics and systems biology analysis of genes network involved in OLP (Oral Lichen Planus) pathogenesis. Arch Oral Biol 2013 Jan [Epub ahead of print].

7. Nicolini C, Bragazzi N, Pechkova E. Nanoproteomics enabling personalized nanomedicine. Adv Drug Deliv Rev 2012; 64:1522-31.

8. Bragazzi NL. From P0 to P6 medicine, a model of highly participatory, narrative, interactive and augmented medicine: some considerations on Salvatore Iaconesi's clinical story. Patient Prefer Adherence 2013. [In press].

9. Del Puente G, Bragazzi NL. The bio-psycho-social model and beyond: its limitations and the need for a new model. A response to Eid's Editorial, the bio-psychosocial model: how accurate and valid is it? Available from: http://www.omicsonline. org/scientific-reports/2161-0487-SR-399.pdf. 10. Del Puente G, Mahamid A, Bragazzi NL.
Correspondence: Nicola Luigi Bragazzi, School of Public Health, Department of Health Sciences (DISSAL), University of Genoa, via Pastore 1, 16132 Genoa, Italy.

Tel. +39.010.3537664 - Fax +39.010.3537669.

E-mail: robertobragazzi@gmail.com

Received for publication: 6 January 2013. Accepted for publication: 6 January 2013.

This work is licensed under a Creative Commons Attribution NonCommercial 3.0 License (CC BYNC 3.0).

@CCopyright N.L. Bragazzi and G. Del Puente, 2013 Licensee PAGEPress, Italy

Health Psychology Research 2013; 1:e5

doi:10.4081/hpr.2013.e5

Health locus of control and multiple sclerosis: a systematic review. Available from: http://www.researchgate.net/publication/234000873_Health_Locus_of_Control _and_Multiple_Sclerosis_A_Systematic_ Review/file/79e4150e026eeedb76.pdf

11. Bragazzi NL. Children, adolescents, and young adults participatory medicine: involving them in the health care process as a strategy for facing infertility issue. Am J Bioeth 2013. [In press].

12. Bragazzi NL, Del Puente G. Musical attitudes and correlations with mental health in a sample of musicians, non-musicians and immigrants: a pilot study. implications for music therapy. Available from: http://www.omicsonline.org/scientificreports/srep366.php. Accessed: January 2013.

13. Bragazzi NL, Del Puente G. Music speaks us: some psychoanalytic considerations on music therapy. Available from: http://www. omicsonline.org/scientific-reports/srep 392.php. Accessed: January 2013.

14. Bragazzi NL, Del Puente G. Panic attacks and possession by djinns: lessons from ethnopsychiatry. Psychol Res Behav Manag 2012;5:185-90.

15. Baba LY, Reading JL. Core competencies for indigenous public health, evaluation and research (CIPHER): a health inequity mitigation strategy. Can J Nurs Res 2012; 44:123-8.

16. Kirmayer LJ. Cultural competence and evidence-based practice in mental health: epistemic communities and the politics of pluralism. Soc Sci Med 2012;75:249-56.

17. Caroppo E, Muscelli C, Brogna P, et al. Relating with migrants: ethnopsychiatry and psychotherapy. Ann Ist Super Sanita 2009;45:331-40. 